\title{
HOLONET: a network for training holography
}

\section{Pedro Pombo, Emanuel Santos}

Pedro Pombo, Emanuel Santos, "HOLONET: a network for training holography," Proc. SPIE 9289, 12th Education and Training in Optics and Photonics Conference, 928910 (17 July 2014); doi: 10.1117/12.2070554

SPIE Event: 12th Education and Training in Optics and Photonics Conference, SPIE. 2013, Porto, Portugal 


\title{
HOLONET: a network for training holography
}

\author{
Pedro Pombo*ab, Emanuel Santos ${ }^{\mathrm{a}}$ \\ aPhysics Department, University of Aveiro, 3810-193 Aveiro, Portugal; \\ ${ }^{b}$ Fábrica Centro Ciência Viva, Aveiro Science Centre, 3810-171 Aveiro, Portugal
}

\begin{abstract}
Holography is an optics technique based on wave physics and lasers with several applications at our day life. The production of holograms involves experimental work based on hands-on activities and creativity. All these elements can contribute to the promotion of experimental teaching of optics and training on holography. The hologram itself acting as a final result from a long process of research and study can enable the engagement of high school students on physics and promote the stimulus on optics learning. Taking these assumptions into account a network of schools working on holography was built involving thirty schools from all country. Holography systems were developed and several handson activities were constructed. During last sixteen years students are working on laser optics and holography producing different kinds of holograms. This study presents all holography labs implemented at schools and it will analyzed the holography systems and materials developed for students. Training strategy will be discussed and holograms obtained by students will be presented. Results obtained show us that holography can be implemented as a strategy for promoting the learning of optics and it is a particular way to involve students on experimental work and lab research. Results obtained during this study will be presented in detail and analyzed with focus on students performance. Educational results, teachers training, prizes and other positive outcomes will be discussed and compared.
\end{abstract}

Keywords: Optics, holography, education, schools

1.

INTRODUCTION

Holography was developed by Gabor in $1947^{1}$ and it is an optics technique based on wave physics, dedicated to wave front reconstruction ${ }^{2}$. This technique is a $3 \mathrm{D}$ imaging system acting as an auto stereoscopic projection that no needs interface between eye and image ${ }^{3}$. The hologram is a device with strong visual impact on observer, and it can promote curiosity about $3 \mathrm{D}$ recording and projection.

HoloNet was created with the goal to promote experimental teaching of optics and taking into account all optics theory involved on holography, its experimental nature and the particularity that an attractive final product is obtained. In 1997 a pilot study was conducted, to evaluate holography as a strategy for education and training on optics and photonics ${ }^{4}$. Based on promising results, an extended research was initiate and a network of schools was create in Portugal 5 .

After sixteen years, a network of thirty secondary schools are working on experimental holography and a HoloLab was implemented at Aveiro Science Centre - Fábrica Ciência Viva. All holography systems and educational materials are developed at holography laboratory of University of Aveiro. All work is supervise with support of teachers from schools and explainers from science centre. The framework implemented in this project, involving scientists, teachers, students, parents and science communicators, has proved to be a key condition for the achievements obtained. The Educational Holography Program developed include: 5 holography systems, 6 holography techniques, 2 travel holography exhibitions, 30 holography school labs, 1 holography lab (HoloLab) dedicated for science outreach and several educational support materials. This HoloNet project has started, being oriented for schools, based on formal science learning ${ }^{6}$. Then it was expanded for science outreach context, based on non-formal science learning ${ }^{7}$. In the beginning of this project all activities were implemented at schools and dedicated to school students. Between 2001 and 2008 activities were extended to school and university students and also to general public. The activities were implemented at schools and at University of Aveiro. Since 2009 activities are implemented at schools, at University of Aveiro and at Science Centers.

*ppombo@ua.pt; phone + 351927994 332; fax + 351234427 053; ua.pt

12th Education and Training in Optics and Photonics Conference, edited by

Manuel F. P. C. Martins Costa, Mourad Zghal, Proc. of SPIE Vol. 9289, 928910

(c) 2014 SPIE, OSA, IEEE, ICO · doi: 10.1117/12.2070554

Proc. of SPIE Vol. 9289 928910-1 


\section{EXPERIMENTAL HOLOGRAPHY}

Through HoloNet, students are involved in a program with strong component on experimental work. This program runs activities in lab ambient and it deals with advanced photonics materials and laser techniques. All students are involved on optics experiments, exploring different experimental setups with the aimed to produce a hologram.

\subsection{Holography Labs}

This project has started with the support of 2 holography labs at Physics Department of University of Aveiro: one dedicated to education and other dedicated to research. During the last years, 30 holography labs were implemented at schools. Typically, these labs are based on $12 \mathrm{~m}^{2}$ dark room with holography system, chemical processing table, water sink and wind fan. In 2003 a portable holography lab was developed based on $4 \mathrm{~m}^{2}$ dark room tent with portable holography system (holokit) and 3 tubs. During last year, HoloLab was implemented at Fábrica Science Centre, based on $60 \mathrm{~m}^{2}$ dark room with RGB laser system, advanced system, workbench, water sink, tables and holograms exhibition.
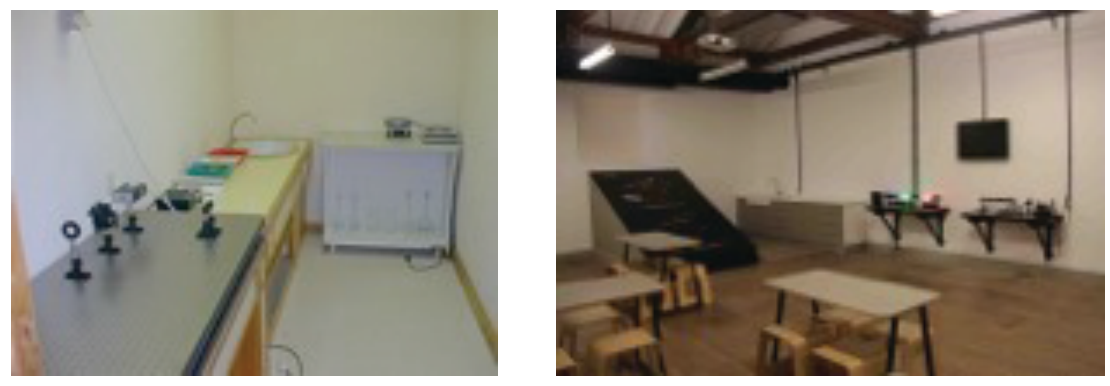

Figure 1. Typically school holography lab and Fábrica Science Centre HoloLab.

\subsection{Holography systems and equipment}

During this project 5 holographic systems were developed to school activities. The first holography system was based on a $1 \mathrm{mX} 1 \mathrm{~m}$ sandbox table ${ }^{8}$. This system involves PVC supports for optics, microscope lens and a $1 \mathrm{~mW} \mathrm{He}-\mathrm{Ne}$ laser. It allows to work with reflection Denisyuk holograms ${ }^{9}$. Then, a second holography system, called advanced system, was developed. This advanced system is very popular. The system was based on $1,2 \mathrm{mX} 0,6 \mathrm{~m}$ breadboard table top, spatial filter, first surface mirrors, beamsplitter, iris, power meter, 5-20 mW He-Ne tube laser and supports. The advanced system allows to work on several holography techniques, namely reflection holography and transmission holography ${ }^{10,11}$. After two immobile systems, work was done to developed portable holography systems. A low cost portable system was developed based on shoebox, sand and a $5 \mathrm{~mW}$ semiconductor laser. Another portable system was developed, based on bench plate, a $5 \mathrm{~mW}$ semiconductor laser and supports. This system, called holokit, is also very popular ${ }^{12}$. Both portable systems allow to work with reflection Denisyuk holograms. Finally, a special RGB laser system was developed for transmission holography. Besides the advanced system, this RGB system was also implemented at Fábrica Science Centre of Aveiro ${ }^{13}$, and it involves a $500 \mathrm{~mW}$ red diode laser, a $100 \mathrm{~mW}$ green diode laser, a $50 \mathrm{~mW}$ blue diode laser, 3 lenses and supports. Figure 2 shows two holography systems.
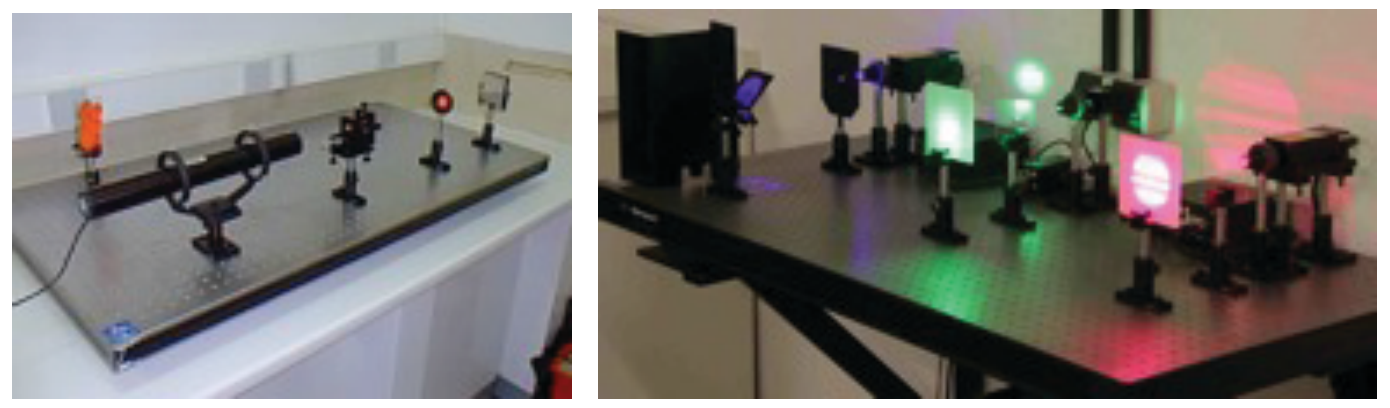

Figure 2. Advanced holography system, and RGB system. 
Table 1 presents all equipments involved in the advanced holography system.

Table 1. Equipment of advanced holography system.

\begin{tabular}{|c|}
\hline Equipment of Holography System \\
\hline Optical breadboard table \\
\hline He-Ne laser $(20 \mathrm{~mW}, 632.8 \mathrm{~nm})$ \\
\hline Spatial filter \\
\hline First surface mirror \\
\hline Iris \\
\hline Manual shutter \\
\hline Plate holder \\
\hline Power meter \\
\hline Supports \\
\hline
\end{tabular}

\subsection{Holography techniques}

There are several techniques for holography that produce different types of holograms. The types of holograms can be organize taking into account the following features: experimental configuration, fringe separation versus emulsion thickness, type of generation, and chemical processing ${ }^{14}$. Relating experimental setup, reflection holography ${ }^{2}$ and transmission holography ${ }^{10}$ were explored by students in detail. Analyzing fringe separation on holograms diffraction patter, it is possible to verify that the majority of students produced volume holograms ${ }^{15}$. Given that students use bleach during hologram processing, it is possible to verify that all holograms were phase holograms ${ }^{16}$. Some students work on interferometric holography ${ }^{17,18}$ using reflection or transmission configurations. Several students work on pseudo colour holograms $s^{19-21}$ and one student had work on a computer program to produce computer generated holograms $\mathrm{s}^{22,23}$. Some secondary students and several younger students are working on scratch holograms ${ }^{24-26}$. Table 2 presents all types of holograms produced by students in HoloNet.

Table 2. Types of holograms produced by students.

\begin{tabular}{|c|}
\hline Type of holograms \\
\hline Reflection holograms \\
\hline Transmission holograms \\
\hline Pseudo colour holograms \\
\hline Interferometric holography \\
\hline Computer generated holograms \\
\hline Scratch holograms \\
\hline
\end{tabular}

Proc. of SPIE Vol. $9289928910-3$ 
A experimental configuration used by students was a single beam reflection holography setup ${ }^{2}$, as shown in the figure 3 .

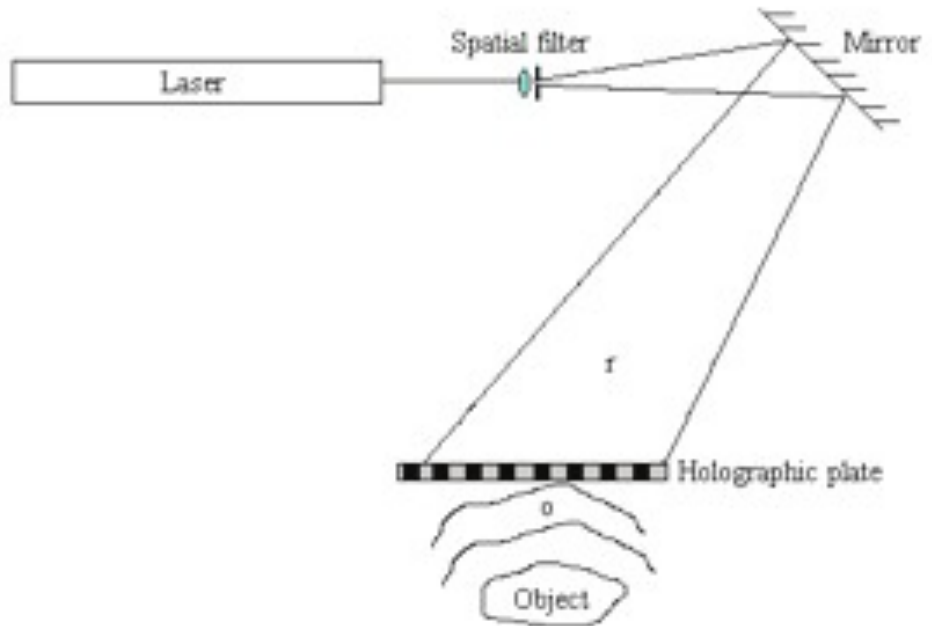

Figure 3. Experimental setup for single beam reflection holograms.

\subsection{Holographic materials and chemical processing}

Different types of emulsions are available for holography, typically presented on plate or film. After several tests the Slavich emulsions PFG-01, based on silver halide, were chosen for schools activities. Students started doing initial experiments and tests on film. When they achieved the control of procedure, plates were used for hologram registration. An extensive research has been done for processing scheme optimization. Analyzing our practical experience and literature, the processing scheme chosen uses the developer SM- $6{ }^{27}$ and the bleach PBU-Amidol ${ }^{27}$, and it is presented in table 3.

Table 3. Processing scheme for Slavich PFG-01 (film and plates) ${ }^{27}$.

\begin{tabular}{|c|c|c|}
\hline Order & Processing solution & Time \\
\hline 1 & Developer: SM-6 & 3 minutes \\
\hline 2 & Rinse: deionised water & 1 minute \\
\hline 3 & Bleach: PBU-Amidol & until clear \\
\hline 4 & Wash: running water & 10 minutes \\
\hline 5 & Dry: cold air & - \\
\hline
\end{tabular}




\subsection{Colour Control on Pseudo Colour Holograms}

In what concerns colour holography, there are different types of holograms that are possible to obtain by students, such as transmission rainbow holograms, monochromatic reflection holograms and multicolour reflection holograms. Most of multicolour reflection holograms are obtained by means of pseudocolour techniques, which require the preswelling and the appropriate manipulation of thickness of the emulsion before exposure for a correct record of different colours. The importance of this technique to Creative Holography motivated a particular emphasis on the behaviour of the emulsion in preswelling conditions, the final quality of the holographic images and the reconstructed wavelengths.

The technique generally used for changing the wavelength and obtaining multicolour holograms implies the preswelling of the emulsion 28,29 . It is necessary to soak the plate into a defined concentration of chemical products, the most well known of which is Triethanolamine (TEA), squeegee the plate, let it dry and clean the glass very well before exposing the plate to the light, which is very time consuming.

The percentages of TEA used for changing the thickness of the Slavich emulsion and achieving the different wavelengths are described in Table $4^{20,30}$.

Table 4. Percentages of TEA for colour control on Slavich PFG-01 emulsion.

\begin{tabular}{|c|c|c|c|}
\hline Time of Soak (min) & Concentration of TEA (\%) & Wavelength (nm) & Colour \\
\hline 2.5 & Water + wetting agent & $635-625$ & Red \\
\hline 2.5 & $1.5 \%$ & $610-605$ & Orange \\
\hline 2.5 & $2 \%$ & $595-580$ & Yellow \\
\hline 2.5 & $3.5 \%$ & $555-550$ & YellowishGreen \\
\hline 2.5 & $5 \%$ & $540-535$ & Green \\
\hline 2.5 & $9 \%$ & $520-490$ & Cyan \\
\hline 2.5 & $10 \%$ & $460-455$ & Blue \\
\hline 2.5 & $13.5 \%$ & $430-420$ & Violet \\
\hline
\end{tabular}

After reaching the correct concentration of TEA in distilled water, that is needed to get the various colours on each type of emulsion, it is possible to produce creative multicoloured holograms made with creative purposes, where the colours are used in a controlled way. After studying the conditions affecting the reconstructed colours it is possible to define a kind of "palette" that helps to select the colours applied on each part of the hologram. The emulsion can be "painted" in an expressive way with different colours not at random, but having the pre-conception of the final result. By this way it is possible to achieve multicolour holograms using TEA to change the thickness of emulsion in silver halide materials. However, the percentage of TEA in preswelling solutions used for a specific wavelength of reconstruction is not equal in all emulsions. Any spectral colour can be obtained during just one exposure, but for obtaining non-spectral colours like magenta or pink it is necessary to do more than one exposure ${ }^{20,30}$.

\section{3.}

\section{EDUCATION AND TRAINING PROGRAM}

Holography is a topic with special ingredients and a winning combination. The special ingredients are science base behavior and state of the art 3D result. These two together gives us a winning combination relating physics, art and technology. Considering that inspiration is needed to produce a good hologram, we think that holography activities can engage students to improve their performance as holographers and by this way, we believe they can learn optics without realizing, which can improve their academic performance. With the idea that holography may be a key role in education 
and training of optics, HoloNet was created and the Educational Holography Program developed with focus on two core areas: formal education (schools) and non-formal education (science outreach).

\subsection{Goals, target and coverage}

The Educational Holography Program of HoloNet is devoted to the general public and to school students. Its main goal is to promote education on optics and holography, to promote knowledge on photonics' apply technologies and to promote training in holography.

The formal education branch is dedicated to school students and teachers, and its goals are: promotion of education in optics and holography, promotion of experimental teaching of optics and promotion of training in holography. The school context involves scientists, science teachers and science and art students. HoloNet at schools has a coverage of 30 high schools distributed throughout Portugal, including Madeira and Açores islands ${ }^{31}$.

The non-formal education branch is dedicated to general public, namely families, teenagers and university students, and its goals are: promotion of knowledge about 3D imaging and holography and promotion of training in holography. The outreach context involves scientists, explainers and the public. Holography outreach runs at University of Aveiro, at Fábrica Ciência Viva Science Centre of Aveiro, at Ciência Viva Science Centre of Sintra, at Ciência Viva Science Centre of Lagos and at Science Museum of University of Coimbra.

\subsection{Framework, products and activities}

HoloNet aims the implementation of a network dedicated to holography. This is achieved through a framework that includes: human resources, material resources and financial resources, and that performs knowledge transfer and product development. The human resources involves teachers, explainers and university staff, such as scientists and researchers. The material resources involves holography labs at University of Aveiro and at Fábrica Science Centre and holographic systems at schools. The financial resources involves investment, funding and profit. During the entire process knowledge transfers occurs associated to teacher training, experimental activities and students workshops. Product development occurs to support the educational program. These products are based on holography exhibitions and educational materials. Table 5 presents a summary of the framework used.

Table 5. Framework of the project HoloNet.

\begin{tabular}{|c|c|c|c|}
\hline & & \multicolumn{2}{|c|}{ Educational Holography Program } \\
\hline & & Outreach & Schools \\
\hline \multirow{5}{*}{ HOLONET } & Human Resources & scientists and explainers & teachers \\
\hline & Material Resources & holography labs & holographic systems \\
\hline & Financial Resources & investment and profit & investment and funding \\
\hline & Knowledge transfer & holography4all & holography@school \\
\hline & Product development & holography exhibitions & educational materials \\
\hline
\end{tabular}


All activities are implemented through the Educational Holography Program. The activities for schools have the name holography@school and the activities for holography outreach have the name holography4all. Holography@school, based on teacher training and experimental workshops for students, includes the following topics: setting up an experimental configuration, beam alignment, spatial filter manipulation, reflection holograms ${ }^{2}$, transmission holograms ${ }^{10}$, pseudo colour holograms (multi colour) ${ }^{19}$, emulsion preparation, holographic interferograms ${ }^{17}$, computer generated holograms $s^{23}$ and scratch holograms ${ }^{24-26}$. The holography@school sessions happen at the Holography Club of the school, during the scholar year and it involves students and a supervisor teacher. The groups of students fluctuate between 3 to 5 for students that want to be involved on a holography research school level project, or the group can be between 20 to 25 for students that just want to be introduced to holography and want to try to do a hologram. The holography4all sessions operate in four different themes: "holography on the go"32, "holographer per one day"33, "open lab" 34 and "summer courses" 35 . "Holography on the go" mission is to take holography near the families, students and general public. With portable holography lab, based on holokit, it is possible to travel to science fairs, open spaces or shopping malls, and involve public to produce simple reflection holograms. This activity can involve a group of 5 persons per hour. "Holographer per one day" is an activity that runs on one saturday per month and during two weekdays per week at the HoloLab of Fábrica Science Centre of Aveiro. During this activity, participants will be holographers per one day, and they can produce a hologram for themselves. This activity is dedicated to families, students and general public, and it can involve a group of 15 to 30 persons per 2 hours. On "open lab" day, school or university students can visit the holography lab of the university and a group of 5 to 10 students can produce a hologram during 90 minutes. During one week on "summer courses", a group of 3 high school students can stay at the University of Aveiro campus to attend an advanced course on experimental holography. There are 3 different courses for 3 students each, dedicated to reflection holography, transmission holography and scratch holograms. During these courses students will follow research topics and will work near scientists, thus they have a life experience in a research environment.

\section{4.}

\section{RESULTS}

The work done during the last years show us that the results obtained can be organized in different subjects.

As educational results, we have obtained:

- 2250 holograms with very good 3D images. These holograms were constructed by school students.

- 2 prizes for HoloNet team, one earned in WONDERS International Science Festival ${ }^{36}$ and one earned in Ciencia en Acción Iberia peninsula and America Latin Science Festival ${ }^{37}$.

- 15 prizes for students earned in National and International Young Scientists Contests.

- 1500 students were involved in advanced holography educational projects.

- 5000 students were involved in holography activities.

As structural results, we have obtained:

- the implementation of 30 holography labs at schools (one in each school), where 16 are based on advanced systems and 14 are based on portable systems.

- the implementation of 1 HoloLab at Fábrica Ciência Viva Science Centre, containing 1 advanced system and 1 RGB system.

As product results (exhibitions), we have obtained:

- the construction of 1 holography exhibition containing: 7 artistic holograms, 1 space for workshops dedicated to scratch holograms and 2 videos screens. This exhibition was sold for Science Centre of Cabo Verde.

- the construction of 1 holography traveling exhibition containing: 9 artistic holograms, 1 portable hololab, 3 interactive exhibits, 1 video screen and 1 space for workshops dedicated to scratch holograms. This exhibition is to rent for shoppings malls.

As product results (educational materials), we have obtained:

- the construction of the holokit ${ }^{12}$. This kit is dedicated to outdoor holography activities and it enables the production of simple reflection holograms. 
- the construction of 1 educational CD dedicated to optics and holography ${ }^{38}$.

- the construction of 1 educational video content dedicated to reflection holograms ${ }^{39}$.

- the construction of 1 educational guide dedicated to Experimental Holography ${ }^{40}$.

As results of promotional material, we have obtained:

-1 website ${ }^{31}$.

- 1 facebook page ${ }^{41}$.

Figure 4 shows some results obtained.
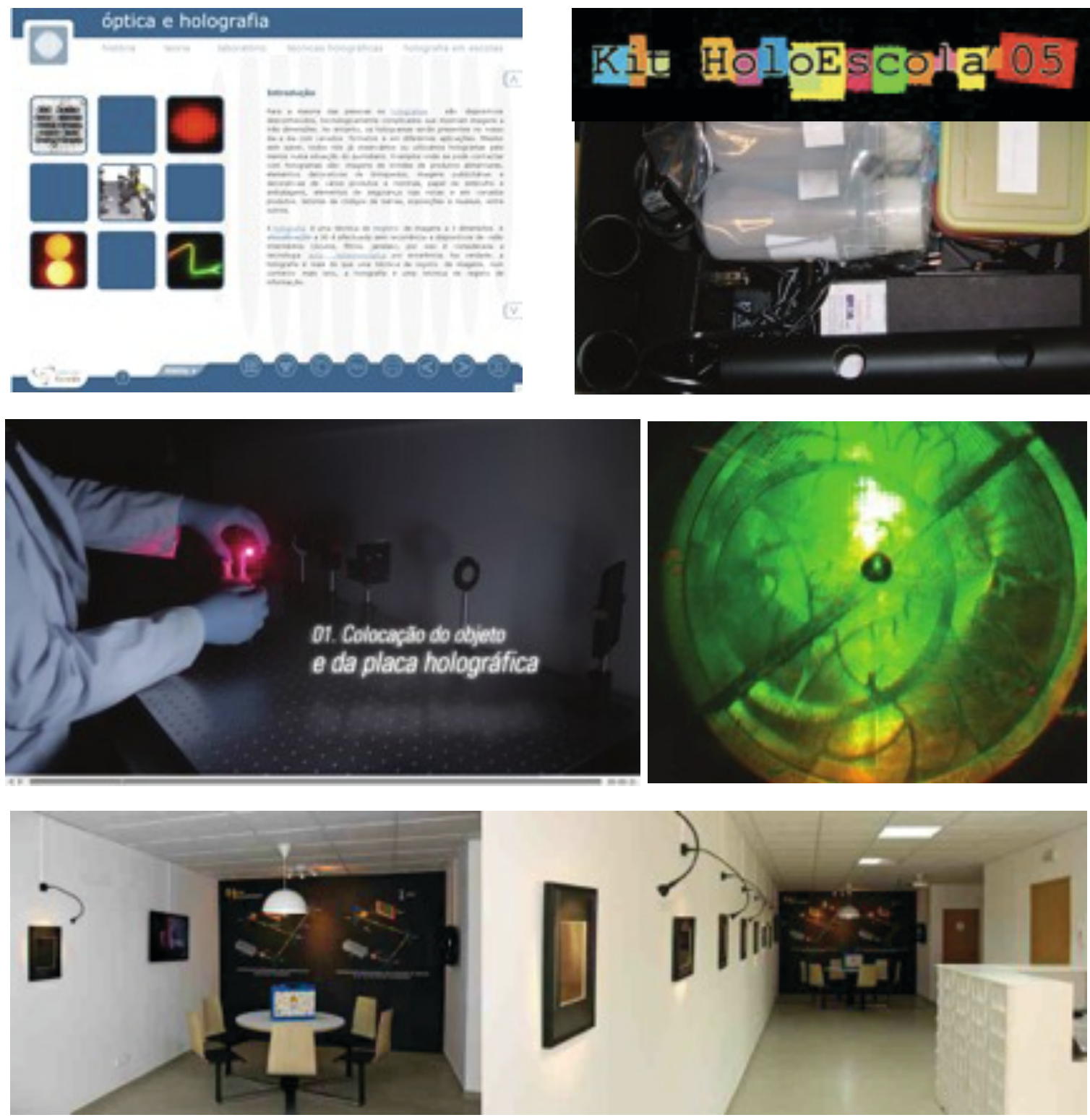

Figure 4. Educational CD layout (top left), holokit (top right), educational video image (left middle), reflection hologram (right middle), holograms exhibition in Cabo Verde (bottom). 
In general, students got very enthusiastic and curious about optics and holography. Some scientific skills and personal attitudes have been promoted such as team work, problem solving, scientific inquiry and self-confidence. An interdisciplinary effect has been achieved linking different areas of knowledge like physics, chemistry and visual arts. The majority of students had been engaged on holography activities and they participated on holograms production actively. The majority of students worked on advanced holography projects doing research at high school level. Some students from art courses had completed art projects for holography. The HoloNet project had a significant impact in the laboratories of schools. A diversified number of educational materials were produced. Holography and 3D imaging are subjects that fascinate the public and hologram exhibitions results in a efficient way to get revenue.

Relating the groups that have started working on experimental holography a increase on students optic's concepts has been achieved namely on reflection, refraction, absorption, interference, diffraction, vision, image formation, laser light and waves. Students' knowledge showed a significant increase on holography concepts namely on theory of holography, differences between holography and photography and holographic applications. Some students have joined the Physics Club of their School and others have started a Holography Club in their school. In general, students get strong training on experimental holography. Taking into account school feedback, we may conclude that holography can promote the learning of physics.

Relating the groups that have been involved on outreach activities, the promotion of scientific culture has been achieved with focus on science learning and public understanding of science. Taking into account families feedback, we may conclude that enthusiasm and curiosity about holography was stimulated and science engagement was fostered.

In conclusion, experimental holography at high school teaching may be considered an efficient tool for contextualised teaching of optics and holographic technique can be a strategy to engage the public into scientific contents.

6.

ACKNOWLEDGMENTS

The authors gratefully acknowledge the financial support of "Ciência Viva Agência Nacional para a Cultura Científica e Tecnológica" through project PEC054.

7.

REFERENCES

[1] Gabor, D., “A new microscopic principle”, Nature, 161, pp. 777-778 (1948).

[2] Denisyuk, Y., "Photographic reconstruction of the optical properties of an object in its own scattered radiation field", Sov. Phys. Doklady, 7, pp. 543-545 (1962).

[3] Saxby, G., "Practical Holography", Institute of Physics Publishing, Bristol and Philadelphia, 3-13 (2004).

[4] Pombo, P., Oliveira, R. M., Pinto, J. L., "Holography for science and art students", Proc. SPIE 4659, 109-114 (2002).

[5] Pombo, P., "HoloRede - Holografia em Rede de Escolas" Concurso Escolher Ciência - da Escola À Universidade, Projeto PEC54, Ciência Viva (2013).

[6] Pombo, P., Oliveira, R. M., Pinto, J. L., "Experimental holography in high school teaching", Proc. SPIE 4149, 232-238 (2000).

[7] Pombo, P., Nogueira, F., "Hologtaphy: science and technology for all", Ciencia en Accíon, CD (2009).

[8] Unterseher, F., Hansen, J., Schlesinger, B., "Holography Handbook: making holograms the easy way", Ross Books, $1^{\text {st }}$ edition (1982).

[9] Denisyuk, Y., "On the reproduction of the optical properties of an object by the wave field of its scattered radiation" Opt. Spectrosc. USSR, 14, 279-284 (1963).

[10] Leith, E. N. and Upatnieks, J., "Reconstructed wavefronts and communication theory". Journal of Optical Society of America, 52, 1123-1130 (1962).

[11] Ackermann, G. K., Eichler, J., "Holography a Practical Approach”, Wiley-VCH, 129-131 (2007).

[12] Arouca C., Sequeira, F., Pombo, P., "Desenvolvimento de um kit para holografia - HoloKit", Seminário Final de Curso, Universidade de Aveiro (2005).

[13] Pombo, P., "Holography: when Art meets Science", ECSITE Annual Conference 2012, 49 (2012).

[14] Hariharan, P., "Optical Holography”, Cambridge University Press, 45-68 (1996). 
[15] Collier, R. J., Burckhardt, C. B., Lin, L. H., “Optical Holography” Academic Press, New York and London, 228-265 (1971).

[16] Bjelkhagen, H. I., "Silver-Halide Recording Materials", Springer (1995).

[17] Abramson, N., "Light in Flight or The Holodiagram", SPIE Press, Washington, 164-238 (1996).

[18] Fernandes, A., Rocha, A. L., Esteves, V., "Hologramas de Transmissão e Módulo de Young”, Intel ISEF 2011, Los Angeles (2011).

[19] Oliveira, R. M., Carretero, L., Madrigal, R., Garzón, M. T., Pinto, J. L., Fimia, A., "Experimental study of colour control on reflection holography", Proc. SPIE (1996).

[20] Pombo, P., Oliveira, R. M., Pinto, J. L., "Color control in reflection holograms recorded in Slavich PFG-01 emulsions", Proc. SPIE 4659, 399-404 (2002).

[21] Fernandes, A., Rocha, A. L., Esteves, V., "Hologramas Multicoloridos", Concurso Internacional de Jovens Cientistas, Lisboa (2009).

[22] Lohmann, A. W., Paris, D. P., "Binary Fraunhofer Holograms, Generated by Computer" Applied Optics, 6 (10), 1739-1748 (1967).

[23] Pombo, P., Arrifano, A., “Computer generated binary Fourier holograms”, Proc. SPIE 6252 (2005).

[24] Abramson, N. H., "Incoherent holography”, Proc. SPIE 4149 153-164 (2000).

[25] Beaty, W. J., "Hand-drawn holograms" Website http://amasci.com/amateur/holo1.html (1995).

[26] Pombo P, Nogueira, F., Lopes, V. Magalhães M. C., Pinto, J. L., "Hand drawn holograms workshop", Proc. GIREP2008, 201 (2008).

[27] Website http://www.slavich.com/holo ufg-red (2013).

[28] Blyth, J., "Pseudoscopic moldmaking handy trick for Denisyuk holographers", Holosphere, 8, 5 (1979).

[29] Hariharan, P., "Pseudocolour images with volume reflection holograms", Opt. Commun., 35, 42-22 (1980).

[30] Oliveira, R. M., Bernardo, L. M., Pinto, J. L., "Multicolour holography: a comparative study", Proc. SPIE 4149, 113-121 (2000).

[31]HoloNet website http://www.holorede.pt.vu (2013).

[32] Website http://www.cienciaviva.pt/projectos/wonders/index.asp?accao=changelang\&lang=en (2013).

[33] Website http://www2.cemed.ua.pt/fabrica/newsletter/sem.asp?i=436 (2013).

[34] Website http://semanaberta.ua.pt/pub/programadtl.asp?id=766\&a=2012\&ent=11\&tp=ent (2013).

[35] http://www.cienciaviva.pt/estagios/jovens/ocjf2013/inscricao.asp?accao=showentidadedetail\&id entidade=34

(2013).

[36] Website http://www.cienciaviva.pt/projectos/wonders/premios.asp (2013).

[37] Pombo P, Nogueira, F., Lopes, V. Magalhães M. C., Pinto, J. L., "Hand drawn holograms", Ciencia en Accíon, CD (2007).

[38] Pombo, P., Nogueira, F., Pinto, J. L., "Education in holography using multimedia and computer simulations", Proc. GIREP2008, 101 (2008).

[39] Website http://www.youtube.com/watch?v=qZC0VA5OxNY (2013).

[40] Website http://issuu.com/science2all/docs/apontamentos holorede (2013).

[41] Website https://www.facebook.com/holorede?ref=nf (2013). 